\section{CREATE AN IDEAL WORKING SPACE}

The Skema 6 is part of a new range of dental units from Castellini. The Skema 6 combines an ergonomic, stylish design with outstanding performance. Conforming to the strict hygiene standards of the dental surgery, Skema 6 allows instruments to be used for surgical and specialist procedures whilst guaranteeing constant operating safety.

With flexibility and functional design, the Skema 6 creates an ideal working space, allowing assistant interaction to be smooth and the dentist to work unhindered. Instruments can be repositioned by lightly touching the capacitive sensor inside the handle on the dentist's module.

\section{SIMPLIFYING 3D ROOT FILLING}

For the reliable, long-lasting threedimensional obturation of root canals, Dentsply Maillefer has launched its new Calamus Dual Downpack and Backfill obturation device.

Calamus Dual saves time and allows clinicians effortless canal access with its ergonomically designed handpiece and feather-touch activation silicone rings. Its user-friendly control panel permits dentists to easily adjust temperature, volume and flow rate settings and boasts two convenient pre-set keys.

With Calamus Dual the risk of root fracture is reduced and its flexible, silver cannulas are suitable for
With extensive-travel arms, the operating ergonomics adjust to each clinical situation in the most efficient and effective way. The assistant's module is on a dual articulated arm and is height adjustable, extendable and able to be folded away to create more working space.

Streamlined, with everything within reach, the Skema 6 enables the dentist to focus on the patient whilst reducing physical stress. The adjustable footrest is made of anti-bacterial material and can be extended and removed for total disinfection. The pneumatic release orbital headrest pivots on three axes to allow optimal positioning of the patient's head.

Reader response number 61

use in curved root canals. Single-use gutta percha cartridges can simply be dropped into the device, minimising the amount of time needed for cleaning and infection control. A filling material indicator carefully monitors the amount of remaining gutta percha for your convenience.

Reader response number 62

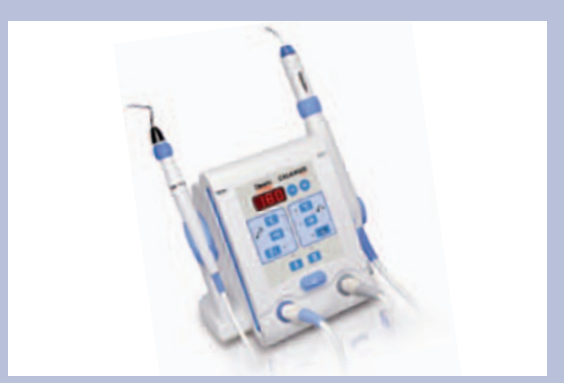

HELP YOUR PATIENTS OVERCOME ANXIETY

The Institute of Hypnotherapy for Medical and Dental Practice (IHMDP) is running two one-day courses specifically for dental professionals, the Hypnodontics Foundation Course and the Advanced Hypnodontics Course.

The Hypnodontics Foundation Course can be taken by all dental staff who work with patients in a dental practice. It covers skills in using hypnosis both formally and informally in interactions with patients, to alleviate anxiety and experience of pain and to facilitate giving treatment to anxious patients, both adults and children.

The Advanced Hypnodontics Course is for graduates of the foundation course or those with previous hypnodontics training. Topics include hypnoanalgesia for patients averse to anaesthetic; reduction/elimination of pain/discomfort during and after dental procedures; improvement of haemostasis during dental procedures; stress management for dental personnel; and hypnosis to reduce/eliminate gagging and for bruxism.

Each course costs £150 and will take place in Central London in October; there is a discount for booking both courses.

Reader response number 64

\section{ANAESTHETICS YOU CAN TRUST}

Septodont has developed its range of dental anaesthetic products specifically with dentists in mind. Septodont is committed to providing products that are 100\% latex free, guaranteeing the highest level of safety possible.

With brands such as Lignospan, Septanest and Scandonest in its portfolio, topical anaesthetics range Xylonor gel and Spray, Septoject needles and the unique Ultra Safety Plus system for preventing needlestick injury, Septodont's name has become synonymous with safe, efficacious dental analgesia.

Reader response number 65
The PALM product suite has been designed to protect all types of corporate healthcare organisations, including clinics, private hospitals, fertility centres, diagnostic and imaging services ers. It is applicable to all sizes of business - from sole traders to large complex enterprises.

All PALM products will meet contractual insurance conditions required by commissioning NHS bodies, including stipulated high aggregate limits of indemnity and the need for the provider to indemnify the service's commissioner.

Reader response number 63 